Article

\title{
Psychological and Socio-Economic Factors Affecting Social Sustainability through Impacts on Perceived Health Care Quality and Public Health: The Case of Vietnam
}

\author{
Quan-Hoang Vuong ${ }^{1,2, *}$, Thu-Trang Vuong ${ }^{3}$, Tung Manh Ho ${ }^{1,4}$ and Ha Viet Nguyen ${ }^{1}$ \\ 1 Centre for Interdisciplinary Social Research, Western University Hanoi, Ha Dong District, \\ Hanoi 100000, Vietnam; tung.ho@wu.edu.vn (T.M.H.); ha.nguyen2@wu.edu.vn (H.V.N.) \\ 2 Centre Emile Bernheim, Université Libre de Bruxelles, 1050 Brussels, Belgium \\ 3 Campus de Dijon, Sciences Po Paris, 21000 Dijon, France; thutrang.vuong@sciencespo.fr \\ 4 Institute of Philosophy, Vietnam Academy of Social Sciences, Dong Da District, Hanoi 100000, Vietnam \\ * Correspondence: hoang.vuong@wu.edu.vn; Tel.: +84-9-0321-0172
}

Received: 15 July 2017; Accepted: 16 August 2017; Published: 17 August 2017

\begin{abstract}
A study on over 2000 patients has been conducted in Hanoi, Vietnam, to explore the influences of psychological and socio-economic factors on the evaluation of healthcare quality and public health by patients. The findings suggest effective health communication and the status of being married are two elements that have the strongest impact on people's positive perceptions about healthcare quality $\left(\beta_{\text {HealthCom }}=0.210, \beta_{\text {otherMaritalstt }}=-0.386, p<0.001\right)$. Young unmarried people and the insured tend to be more critical of healthcare quality $\left(\beta_{\text {Age }}=-0.005, p<0.05\right.$; $\beta_{\text {yesHealthIns }}=-0.208, p<0.001$ ). At the same time, a higher BMI and better view of health care quality are linked to negative opinions about community health. These outcomes suggest that in order to maintain collective health as part of social sustainability, the Vietnamese government should pay attention to infrastructure improvement, insurance system reforms, and communication of personal health care knowledge.
\end{abstract}

Keywords: social health sustainability; public health; health insurance; health communication; health-related environmental issues

\section{Introduction}

According to studies in both developed and developing countries, the public, worldwide, is becoming increasingly concerned about sustainable healthcare. In the United Kingdom and the United States, studies reveal that the care delivered did not often meet the subjective expectations of patients regarding quality [1-3]. A survey in the United States reported that patients only received half of the recommended treatment process [4]. The same goes for nations in development. In Kenya, for example, only $56.9 \%$ of malaria patients received the recommended treatment, $30.4 \%$ were treated with minor errors, and $12.7 \%$ received inappropriate treatment [5].

The analysis of attitudes and satisfaction among patients towards the quality of healthcare services has been initiated a long time ago with a wide range of research papers [6]. Rooney et al. announced a report introducing a set of quantifiable indicators used to evaluate healthcare quality in hospitals over time [7]. More recently, researchers have suggested evaluations based on direct clinician observation and perception of patients be used simultaneously to improve the reliability of the data [8]. This is because, in many cases, the opinion of the patient can be affected by certain factors, particularly their own subjective and uninformed cost-benefit analysis, and may not fully reflect the quality of the health care provider [9]. Financial aspects of health care have been shown to 
have a great impact on decision-making among patients [10] which, in turn, potentially affects the sustainability of the communities to which they belong [11]. Asymmetric information may come into play as well, suggesting that communication regarding health care is an essential element factoring in the perception of health care quality by patients.

Private providers often offer services perceived by users to be more attractive but with a higher price [12]. This however is not true in all countries. Rao et al. indicated that the perceived quality at public facilities in India was marginally favourable [13]. In Zaire, on a local level, the interpersonal qualities displayed by some nurses sometimes helped compensate for the negative effects of the costs, and even increased the level of utilisation of some health centres [14]. Specific components of interpersonal care, such as responsiveness of nurses to complaints and reassurance from doctors, were initially thought to be the main determinants of perceived quality of care; however, empirical studies show that these factors are not strong predictors [13-18]. The quality of care as perceived by patients was found to depend on certain contextual and intervening conditions pertaining to the broader environment, the organisation, and personal factors of the nurse and patient [19].

The rapid changing of human habitat around the world has long posed the question of natural, and, consequently, social sustainability, because a community must be able to keep its population in good shape in order to sustain itself. This maintenance of public health is tied to the living environment: Varied environments result in different health status [20-22]. In the United Kingdom, different areas have different mortality rates [23-25]. Intuitively, an unhealthy environment, including perverse effects of climate change, also shows negative influences on not only people's health [26-28], but their perception of health care quality, as well [29]. However, nature is not the sole factor in sustaining a community; human health is also largely a social matter. In fact, the relationship between personal and public health has been in focus in the recent years. Questions over whether health management was personal or social responsibility were raised; the debate tied between the consequences of unresolved inequities in access to health care, especially in developing countries [30,31], versus an insistence on personal liberty and refusal of public health management [32]. There is, thus, an intriguing connection between personal perceptions of health care and that of the social system, which called for an investigation linking these elements together.

With rising concern about health-related, as well as sustainability, issues in developing countries, this study aims to add findings on the Vietnamese population's view on health care. People-perceived healthcare quality and public health status will be considered in relation to the factors of health insurance, age, body mass index (BMI), marital status, healthcare costs, health communication, and the impact of friends and relatives.

In this paper, two main issues are discussed: (1) the factors regarding demographics, society, and psychology affecting the patient's evaluation of health care services quality; and (2) the influence of body mass index, perceived quality of health services, and health communication on people's perceptions of public health.

\section{Materials and Methods}

The data for this article was derived from a survey conducted in Hanoi, Vietnam by a team of professional investigators from Vuong and Associates in September 2016. This study collected data on a range of socio-economic and demographic indicators. Participants were patients, chosen at random with no discriminatory criteria; response rates were approximately $83 \%$ ( 5 out of 6 ). The questions were direct and simple, and participants were instructed by the interviewer to ensure that each questionnaire was filled correctly. The average time taken to collect a questionnaire was 10-15 min. Investigators have been thoroughly trained in order not to interfere with data sampling.

Data was extracted from the dataset of periodic general health examinations, which was collected and prepared by a data team from Vuong and Associates during September to November 2016. Ethical standards of the survey were regulated in the license of V\&A/07/2016 (12 September 2016). 
Raw data was first recorded in Excel (v.2010; Microsoft, Redmond, WA, USA) and then executed in R (v3.3.1; Bell Labs, Murray Hill, NJ, USA).

We acknowledge that the dataset is Hanoi-based and thus presents a major geographical limitation. A nationwide survey would conduct to a different dataset showing regional differences as well as shifting in behaviours. For the time being, such a survey would require resources beyond our capacity.

\subsection{Measures}

The study took into account the following demographic factors, social-economic situation, and the mentality and perception of patients. These indicators will be explained in the following section.

Explanatory variables concerning demography included age ("Age") and marital status ("Maritalstt"). With regards to socio-economic factors, the survey tracked whether the patient has a health insurance (represented by "HealthIns", a categorical variable responded with "yes" or "no"), and the quality of health communication as evaluated by the patient ("HealthCom"). Heath communication was defined in this study as information concerning health, diffused on mass media; its value was derived from the average score given by patients for the following four criteria: Sufficiency, Attractiveness, Emphasis, and Popularity. They were scored from 1 (lowest) to 5 (highest).

Factors related to the mentality and perception of patients included cost, family and medical experience. Namely, patients were asked to estimate an affordable cost for a general examination ("AffCost"). This variable was divided into 3 levels: "low" (<VND 1 million), "med" (between VND 1 and 2 million), and "hi" (>VND 2 million). It was also taken into consideration whether or not the patient had friends or relatives who have experienced prolonged treatment (represented by "AcqTrmt", a categorical variable with two responses, "yes" and "no"). Participants were furthermore questioned on their experience (or lack thereof) of taking care of patients ("ExpCare", a categorical variable admitting two options "yes" and "no").

The height and weight of patients were recorded and used to calculate their BMI, which then served as a representative indicator in our analysis. Health care quality ("SerQual") was measured as the average value of the scores given by patients for the following five criteria: Tangibles, Reliability, Responsiveness, Assurance, and Empathy. These elements were scored from 1 (lowest) to 5 (highest). Finally, patients were asked of their perception of public health ("ComHthPers"), and their answers were limited to four options: Very optimistic ("Good"), Moderately optimistic ("Quite"), Pessimistic ("Bad"), and Unknown (“Unknown").

\subsection{Methodology}

To examine the impact of demographics, society and psychology on the patient's evaluation of health care services quality, multivariate linear regression was used with the general model as follows:

$$
Y=\alpha+\beta_{1} X_{1}+\beta_{2} X_{2}+\cdots+\beta_{k} X_{k}
$$

with the condition that $k$ independent variables $X_{i}$ must have the same sample size $n$ to the dependent $Y$. $Y$ is a numerical variable, while $X_{i}$ can be numerical or categorical. Data, after being processed in $\mathrm{R}$, gave the values of $\beta_{i}$, which represented the linear impact of $X_{i}$ on $Y$, namely the value of "SerQual" in this research.

In order to examine the influence of BMI, perceived health care services quality and communication on the patient's perception of public health, a baseline-categorical logit model (BCL) was employed due to its dominant features in predicting the probabilities of $Y$ in different conditions of $x$. Estimations were computed using logit BCL according to [33].

The general equation of the baseline-categorical logit model was:

$$
\ln \left[\pi j(\mathbf{x}) /\left(\pi_{J}(\mathbf{x})\right]=\boldsymbol{\alpha}_{j}+\boldsymbol{\beta}^{\mathrm{T}}{ }_{j} \mathbf{x}, j=1, \ldots, J-1,\right.
$$


in which $\mathbf{x}$ was the independent variable and $\pi_{j}(\mathbf{x})=\mathrm{P}(Y=j \mid \mathbf{x})$ its probability. Thus $\pi_{j}=\mathrm{P}\left(Y_{i j}=1\right)$, with $Y$ being the dependent variable. In the logit model, the probability of an event was computed as:

$$
\pi_{j}(\mathbf{x})=\left[\exp \left(\boldsymbol{\alpha}_{j}+\boldsymbol{\beta}^{\mathrm{T}} \mathbf{x}\right)\right] /\left[1+\sum^{\mathrm{J}-1}{ }_{\mathrm{h}=1} \exp \left(\boldsymbol{\alpha}_{h}+\boldsymbol{\beta}^{\mathrm{T}}{ }_{h} \mathbf{x}\right)\right],
$$

with $\sum_{j} \pi_{j}(\mathbf{x})=1$ and $\beta_{J}=0$; in which $n$ was the number of observations in the sample, $j$ the categorical values of an observation $i$, and $h$ a row in basic matrix $\mathbf{x}_{i}$ [34]. The statistical significance of predictor variables in the model were determined based on $z$-value and $p$-value; with a $p<0.05$ being the conventional level of statistical significance required for a positive result.

\section{Results}

\subsection{A Descriptive Statistics Analysis}

A few descriptive statistics are displayed in the table below:

It could be observed in Table 1 that younger people ( $<30$ years old) accounted for over a half of the respondents. Some other noteworthy points emerge, such as over $82 \%$ of participants had health insurance, and three-quarters of them reported they used to take care of patients.

Table 1. Some key descriptive statistics.

\begin{tabular}{|c|c|c|}
\hline Characteristics & $N$ & Percentage $(\%)$ \\
\hline \multicolumn{3}{|l|}{ Age "Age" } \\
\hline$<30$ & 1306 & 63.15 \\
\hline $30-49$ & 643 & 31.09 \\
\hline$\geq 50$ & 119 & 5.76 \\
\hline \multicolumn{3}{|l|}{ Health Insurance "HealthIns" } \\
\hline Yes & 1700 & 82.21 \\
\hline No & 368 & 17.79 \\
\hline \multicolumn{3}{|l|}{ Marital Status "Maritalstt" } \\
\hline Married & 1186 & 57.35 \\
\hline Unmarried & 877 & 42.41 \\
\hline Other (widowed, divorced, etc.) & 5 & 0.24 \\
\hline \multicolumn{3}{|l|}{ Perception of public health "ComHthPers" } \\
\hline Good & 337 & 16.30 \\
\hline Relatively good despite problems remain & 722 & 34.91 \\
\hline Not good & 749 & 36.22 \\
\hline Unknown & 260 & 12.57 \\
\hline \multicolumn{3}{|l|}{$\begin{array}{l}\text { Affordable cost for a general health examination } \\
\text { ("AffCost") }\end{array}$} \\
\hline Less than VND 1 mn (“low”) & 876 & 42.36 \\
\hline Between VND 1-2 mn ("med") & 909 & 43.96 \\
\hline Higher than VND 2 mn (“hi") & 283 & 13.68 \\
\hline \multicolumn{3}{|c|}{$\begin{array}{l}\text { Having friends/relatives once experienced prolonged } \\
\text { treatment "AcqTrmt" }\end{array}$} \\
\hline Yes & 917 & 44.34 \\
\hline No & 1151 & 55.66 \\
\hline \multicolumn{3}{|c|}{ Having experience of taking care someone ill "ExpCare" } \\
\hline Yes & 1486 & 71.86 \\
\hline No & 582 & 28.14 \\
\hline \multicolumn{3}{|c|}{ Perceptions of health services quality ("SerQual") } \\
\hline From 1 to $<2$ points ("low") & 60 & 2.90 \\
\hline From 2 to <4 points ("med") & 1291 & 62.43 \\
\hline From 4 to 5 points ("hi") & 717 & 34.67 \\
\hline \multicolumn{3}{|l|}{ BMI } \\
\hline <18.5 (under-weight) & 408 & 19.73 \\
\hline $18.5-22.99$ (normal) & 1242 & 60.06 \\
\hline $23-24.99$ (pre-obese) & 279 & 13.49 \\
\hline 25-29.99 (obese level I) & 128 & 6.19 \\
\hline$\geq 30$ (obese level II) & 11 & 0.53 \\
\hline
\end{tabular}


Popular perceptions of public health were rather negative, as only $16.3 \%$ felt optimistic about the current state of public health. This was partly reflected in their evaluation of service quality. For nearly two-thirds of the patients surveyed, health care quality in hospitals scored under 4 points (majorly from 2 to $<4$ points).

While perception of public health was measured as a discrete variable, the quality of health care services as assessed by patients was considered a continuous variable within the scope of this study (refer to Section 2.1. Measures for more details on the variable "SerQual"). The values of this variable, as well as each of its five sub-elements, were shown in the following table among other continuous variables.

Table 2 presented the mean value, standard errors, and 95\% confidence interval of key variables mentioned in the study. Healthcare service quality was evaluated by patients as a little more than acceptable, given its mean score of 3.55/5 (95\% CI $=3.51-3.59)$. Regarding remaining variables, $\mathrm{BMI}$ is at a normal level and the mean age is quite young, reflecting the reality of Vietnam's young population.

Figure 1 provides other figures from the dataset.

Table 2. A few descriptive statistics for continuous variables.

\begin{tabular}{lccc}
\hline \multicolumn{1}{c}{ Characteristics } & Average & SD & 95\% CI \\
\hline Age & 29.17 & 10.09 & $28.74-29.60$ \\
BMI & 20.85 & 2.69 & $20.73-20.97$ \\
Health services quality & 3.55 & 0.94 & $3.51-3.59$ \\
Tangibles & 3.61 & 1.06 & $3.56-3.65$ \\
Reliability & 3.57 & 1.08 & $3.53-3.62$ \\
Responsiveness & 3.38 & 1.26 & $3.33-3.44$ \\
Assurance & 3.69 & 1.09 & $3.65-3.74$ \\
Empathy & 3.47 & 1.25 & $3.42-3.52$ \\
Quality of health communication & 2.83 & 1.17 & $2.78-2.88$ \\
\hline
\end{tabular}

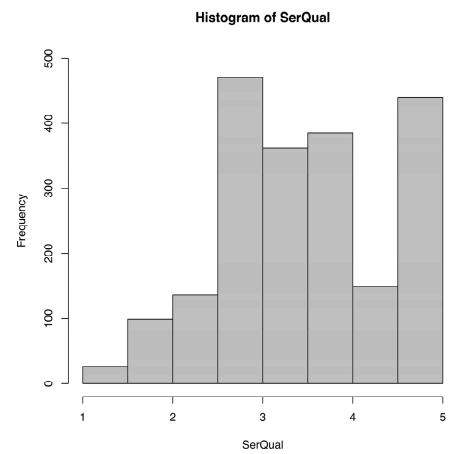

(a)

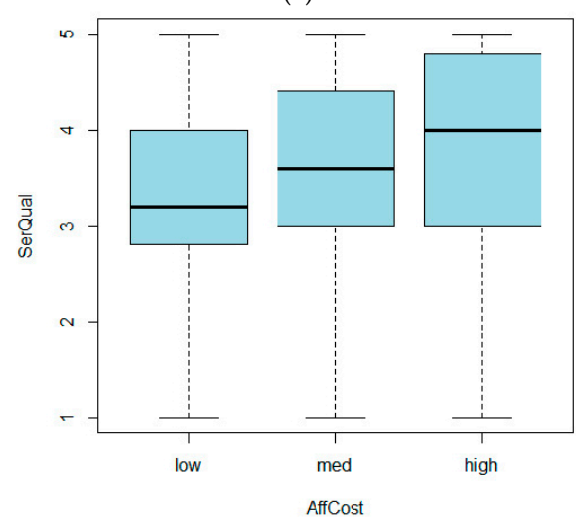

(c)

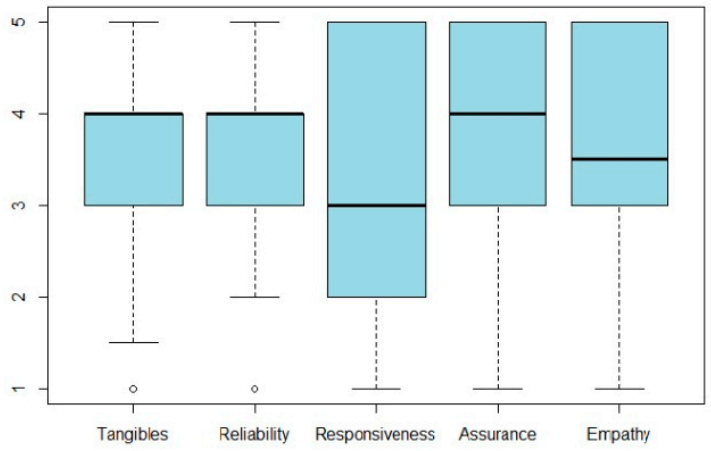

(b)

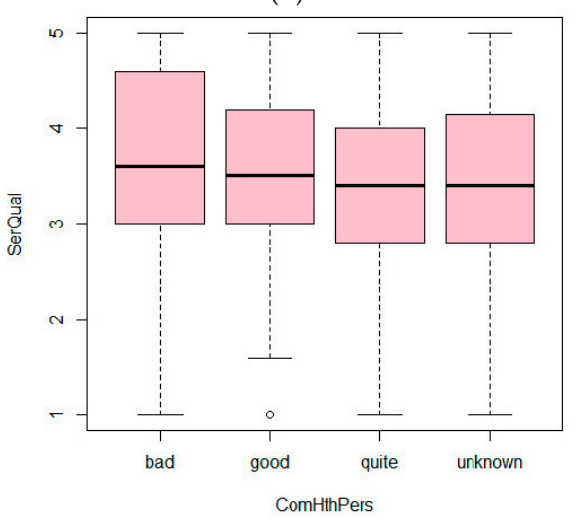

(d)

Figure 1. Cont. 


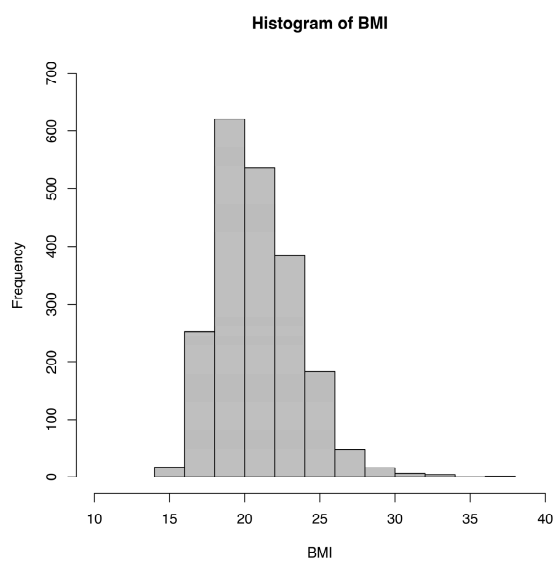

(e)

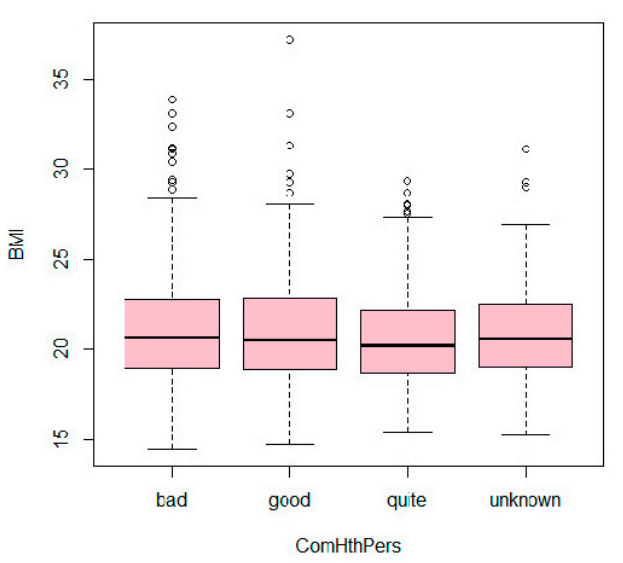

(f)

Figure 1. Distributions of SerQual and BMI measures following some key variables concerning social sustainability. (a) Histogram of SerQual; (b) Distribution of values across key quality measures; (c) SerQual measure against cost level; (d) SerQual measure against community health perceptions;

(e) Histogram of BMI; (f) Distribution of BMI value against community health perceptions.

\subsection{Factors Affecting Health Care Quality as Perceived by Patients}

Factors that were considered influential to popular attitude towards the quality of medical care include: demographic elements, namely age and marital status; socio-economic elements, such as health insurance and quality of health communication; and personal, subjective elements, such as affordable cost limits, having friends/relatives in prolonged treatment, and experience of taking care of patients. (For more details on the measurement of these indicators, refer to Section 2.1. Measures above.)

Regression was performed to determine the impact of these factors on the perception of patients on health care service quality. Results are shown in Table 3.

Table 3. The impact of various factors on health care service quality as perceived by patients.

\begin{tabular}{|c|c|c|c|c|c|c|c|c|}
\hline Intercept & Age & HealthCom & $\begin{array}{l}\text { HealthIns } \\
\text { "Yes" }\end{array}$ & $\begin{array}{l}\text { Maritalstt } \\
\text { “Other" }\end{array}$ & $\begin{array}{l}\text { AffCost } \\
\text { "Hi" }\end{array}$ & $\begin{array}{l}\text { AffCost } \\
\text { "Low" }\end{array}$ & $\begin{array}{l}\text { AcqTrmt } \\
\text { "Yes" }\end{array}$ & $\begin{array}{l}\text { ExpCare } \\
\text { "Yes" }\end{array}$ \\
\hline$\beta_{0}$ & $\beta_{1}$ & $\beta_{2}$ & $\beta_{3}$ & $\beta_{4}$ & $\beta_{5}$ & $\beta_{6}$ & $\beta_{7}$ & $\beta_{8}$ \\
\hline $\begin{array}{l}3.403^{* * *} \\
{[31.087]}\end{array}$ & $\begin{array}{l}-0.005^{*} \\
{[-1.990]}\end{array}$ & $\begin{array}{l}0.210^{* * *} \\
{[10.771]}\end{array}$ & $\begin{array}{c}-0.208^{* * *} \\
{[-4.122]}\end{array}$ & $\begin{array}{c}-0.386^{* * *} \\
{[-7.986]}\end{array}$ & $\begin{array}{c}0.160 * * \\
{[-5.156]}\end{array}$ & $\begin{array}{c}-0.214^{* * *} \\
{[-5.156]}\end{array}$ & $\begin{array}{l}-0.122 * * \\
{[-3.064]}\end{array}$ & $\begin{array}{c}0.198^{* * *} \\
{[4.509]}\end{array}$ \\
\hline
\end{tabular}

It could be seen in Table 3 that all standardized coefficients in the model were statistically significant with $p<0.05$, which confirmed the correlation between these factors and people-perceived health quality. This relationship was represented in the equation below:

$$
\begin{aligned}
\text { SerQual }= & 3.403-0.005 \times \text { Age }+0.210 \times \text { HealthCom }-0.208 \times \text { yesHealthIns }- \\
& 0.386 \times \text { otherMaritalstt }+0.160 \times \text { hiAffCost }-0.214 \times \text { lowAffCost }- \\
& 0.122 \times \text { yesAcqTrmt }+0.198 \times \text { yesExpCare }
\end{aligned}
$$

The factors affecting health care quality evaluations could be divided into two groups: (1) positive factors, and (2) negative factors.

Among the factors in Group 1, health communication ("HealthCom") had the strongest influence, with $\beta_{2}=0.210(p<0.001)$. This coefficient implies that, controlling for other factors, when health communication increased one point, health services quality increased 0.21 points on average. In addition, affordable cost estimated at over VND 2 million ("AffCost" at "hi") and experience of 
caring for patients ("ExpCare" at "yes") also belonged to this group. This showed that the willingness to pay a periodic general health examination at a high cost and the experience of taking care of patients also improved the general attitude towards healthcare services.

Group 2 consisted of age, possession of insurance ("HealthIns" at "yes"), a marital status other than married or unmarried ("Maritalstt" at "other"), an affordable cost of under VND 1 million ("AffCost" at "low") and experience of prolonged treatment ("AcqTrmt" at "yes"), all of which had negative coefficients. It was worth noting that, surprisingly, possession of health insurance could lead to patients' bad impression of healthcare services quality, with coefficient $\beta_{3}=-0.208(p<0.001)$ indicating that insured people evaluate medical care quality 0.208 points lower than the uninsured (other factors controlled). Furthermore, the negative values of $\beta_{1}, \beta_{4}$, and $\beta_{7}$ also indicated that older people who were widowed or divorced and those with friends or relatives who had experienced or were experiencing prolonged treatment tend to be more critical in evaluating the quality of services they receive. In other words, young people, married or unmarried people, and those surrounded with people in stable health conditions were more likely to express positive feelings on health care quality.

\subsection{BMI, Quality of Health Communication, and Healthcare Quality Affect People's Perception of} Public Health

The BCL model was employed to examine the influence of BMI, health care service quality and health communication quality as perceived by patients on patients' view of public health. Table 4 provides the estimates.

Table 4. Estimation result of "ComHthPers" following "BMI", "SerQual”, and "HealthCom".

\begin{tabular}{ccccc}
\hline & Intercept & "BMI" & "SerQual" & “HealthCom" \\
\cline { 2 - 5 } & $\beta_{\mathbf{0}}$ & $\beta_{\mathbf{1}}$ & $\beta_{2}$ & $\beta_{3}$ \\
\hline $\operatorname{logit}($ bad I quite) & $-1.692^{* * *}$ & $0.064^{* *}$ & $0.319^{* * *}$ & $-0.263^{* * *}$ \\
& {$[-3.652]$} & {$[3.192]$} & {$[5.343]$} & {$[-3.443]$} \\
$\operatorname{logit}($ good I quite) & $-2.811^{* * *}$ & $0.050^{*}$ & $0.141^{\mathrm{c}}$ & $0.176^{*}$ \\
& {$[-4.885]$} & {$[2.007]$} & {$[1.840]$} & {$[2.397]$} \\
\hline
\end{tabular}

Note: Signif. codes: 0 *** $0.001{ }^{* *} 0.01^{*} 0.05^{c} ; z$-value in square brackets. Residual deviance: 3699.62 on 3608 df. Log-likelihood: -1849.81 on $3608 \mathrm{df}$.

With 0.05 being the level of significance, all estimated coefficients in the model were statistically significant, except for $\beta_{2}$ in the logit(good/quite) model. Therefore, it could be affirmed that there existed a relationship between the above variables.

Regression equations were established as follows:

$$
\begin{aligned}
& \ln \left(\pi_{\text {bad }} / \pi_{\text {quite }}\right)=-1.692+0.064 \times \text { BMI }+0.319 \times \text { SerQual }-0.263 \times \text { HealthCom } \\
& \ln \left(\pi_{\text {good }} / \pi_{\text {quite }}\right)=-2.811+0.050 \times \text { BMI }+0.141 \times \text { SerQual }+0.176 \times \text { HealthCom }
\end{aligned}
$$

Compared to health communication and health care quality (both reported as perceived by patients), BMI had a weaker impact on people's perception of public health, with a coefficient of merely 0.064 . It could be calculated that a person of average BMI (20.85), evaluating healthcare quality as average (3.55 points) and rating health communication quality at the lowest point (one point), would have a $55 \%$ probability of having a pessimistic ("bad") view on public health. The numerical value (0.555) was computed using Equation (6).

Using the same methods, we calculated probabilities of other variables in other conditions. These probabilities were presented in Figure 2. Figure 2a illustrated different perceptions of public health of the people with different BMI. People with higher BMI tended to be more negative about public health. This propensity was more obvious when BMI exceeded the average point, which was revealed through opposite trends and changes in slopes of the lines representing a very optimistic 
perception ("good") of the current state of public health and its pessimistic counterpart ("bad") at $\mathrm{BMI}=20.85$. Observing the line representing optimism in public health, one could remark that the probability of optimistic perception increased mildly when BMI increased, which seemed to show that an increased BMI boosted pessimistic perceptions as well as very optimistic ones. However, not only the likelihood of optimistic perception about public health was generally not high, its increase was insignificant, particularly in contrast with the stark drop in the probability of moderately optimistic perception ("quite"). It was safe to say that in general, a higher BMI resulted in less optimism in the current state of public health.

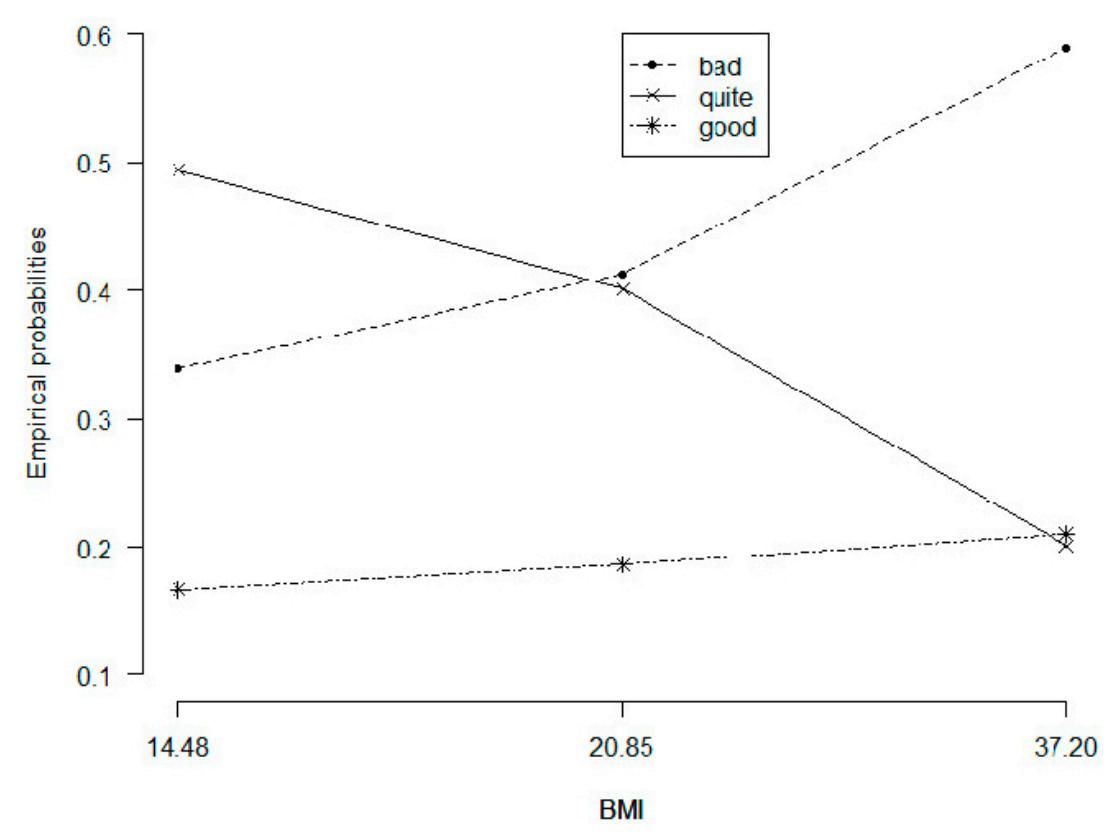

(a)

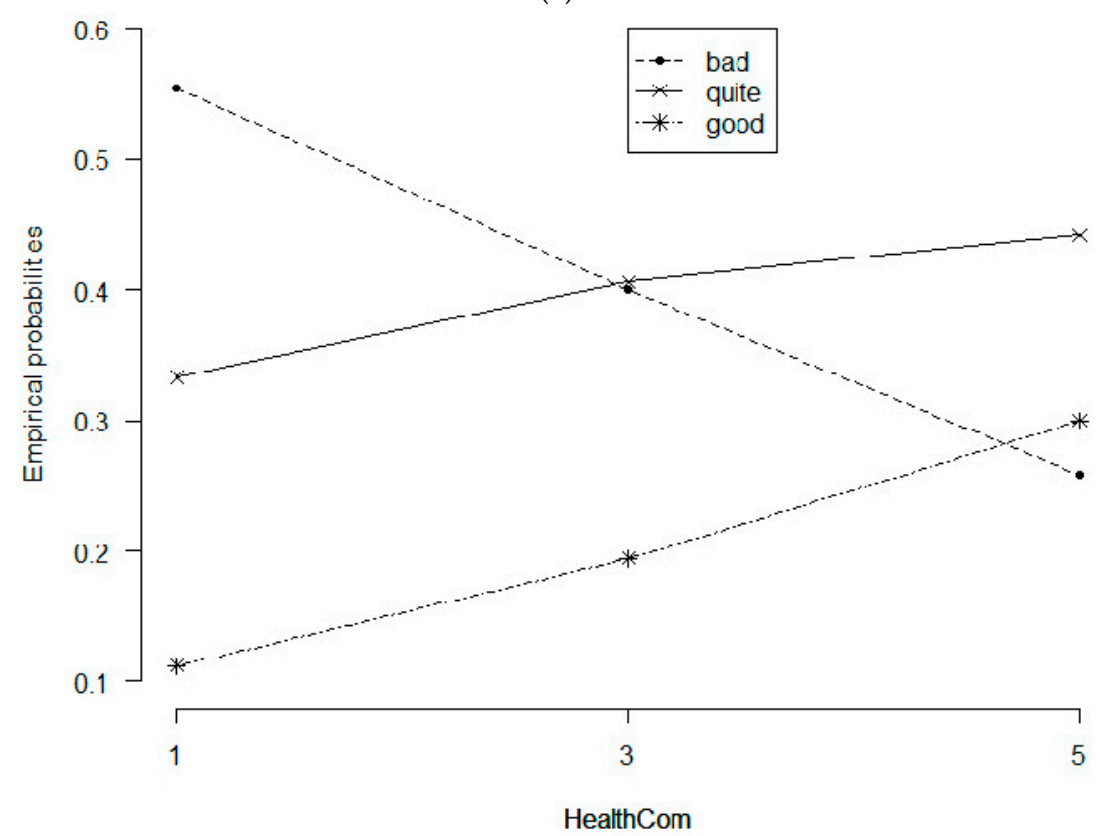

(b)

Figure 2. Cont. 


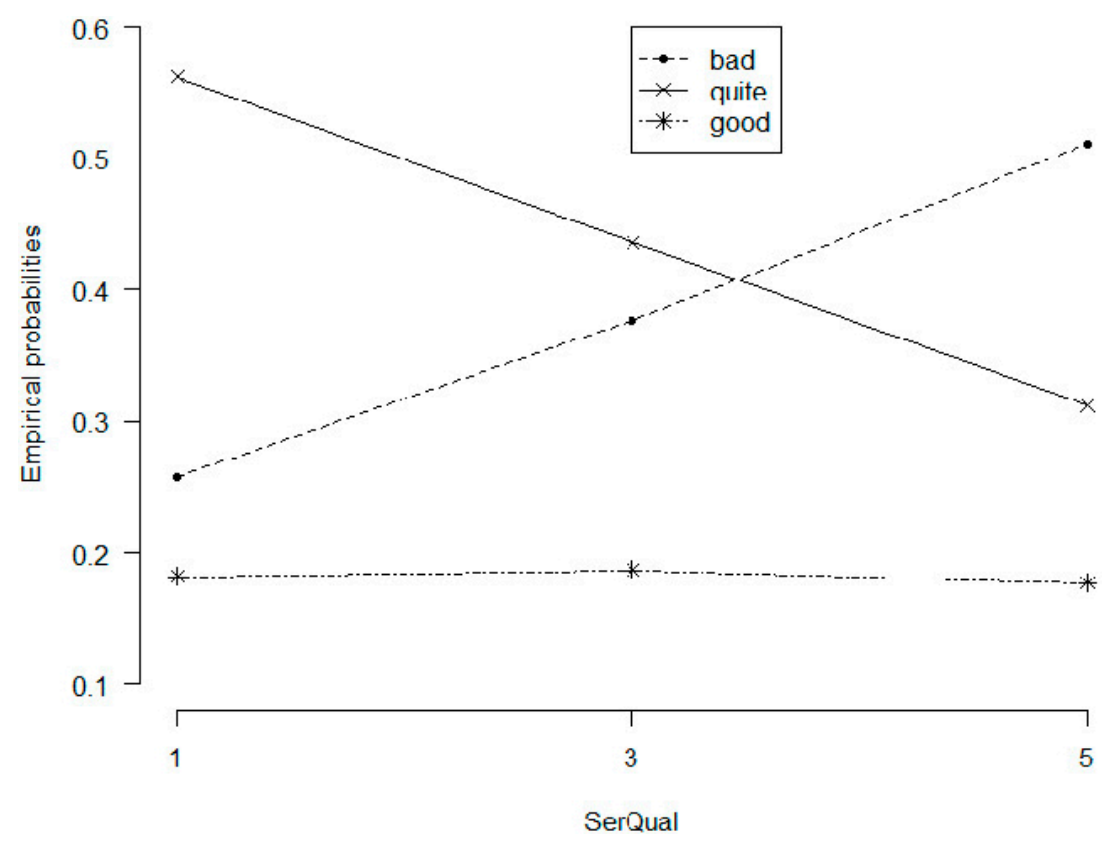

(c)

Figure 2. Changes in probabilities of people's perception towards BMI, health communication and healthcare quality. Notes: Values "bad", "quite" and "good" represent the perceptions of "not good", "quite good" and "good" about public health; "SerQual" = 3.55; "HealthCom" = 2.83 (Figure 2a); “BMI" = 20.85, "SerQual" = 3.55 (Figure 2b); “BMI" = 20.85; and "HealthCom" = 2.83 (Figure 2c). (a) Probabilistic trends of health community perceptions with varying BMI levels; (b) Probabilistic trends following varying health communication levels; (c) Probabilistic trends following general service quality measure.

Figure $2 \mathrm{~b}$ represented the influence of health communication on how people perceived health care service quality. Media indeed had a powerful impact on popular perception: when moving from the lowest score to the highest score of service quality as rated by patients, both lines representing very optimistic and moderately optimistic views regarding public health went up, while pessimistic perception went down in probability. The likelihood of a very optimistic view of public health might go up to $74 \%$ at its peak. This means that when health communication is sufficient, attractive, emphasized, and popular, public perception on the status of collective health in a community can be improved drastically.

Similarly, Figure 2c once again affirmed the modest level of optimism concerning public health, with lines depicting changes in probabilities of popular perception about community health according to perceived health care quality. The probability of very optimistic perception went flat with all points lying under $20 \%$, even decreased slightly (from 18.7 to $17.7 \%$ ) when health service quality score rose from three to five points. Notably, the likelihood of pessimistic views fluctuated from $26 \%$ to $51 \%$ in an upward trend when healthcare quality increased, and vice versa for that of moderate optimism. In summary, improvement in patient-based evaluation of health care quality did not encourage and even reduced good feelings about public health.

\section{Discussion}

Based on the above results, this section will evaluate the influence of the aforementioned factors on social sustainability through their impact on health care quality, as well as public health.

Quality of health communication, willingness to pay high treatment costs, being married, being young and having experience in taking care of patients-these are factors that could increase positivity in patient attitude towards health care services, which is in line with recent empirical 
findings on determinants of patient satisfaction [35]. Of these factors, health communication and marital status are the most influential. When the quality of health communication rises, people receive more information, both in quality and quantity; their assessment will be more informed and reasonable instead of being characterised by flawed remarks due to a lack of information, which leads to a lack of empathy for medical staff, who usually work in a stressful environment $[34,36]$.

In the same vein, similar explanations go for those who have had experience taking care of someone ill. From their experience, they have a deep empathy for the job of taking care of patients, like doctors and nurses. This is still true when comparing those already married and others (single, widowed, or separated). On average, married people assess the quality of health services to be 0.386 points higher than those who have another marital status. We can assume that marriage, primarily, involves health communication and is related to better medical knowledge through an increased amount of (reliable) information. Previous studies have even found family is the primary unit for health education in all countries, despite the country's level of economic development [37]. Family members can be a source of healthcare information and can affect other members' self-care attitude and preventative behaviours [38].

Health care costs and quality have a mutually influential relationship. When patients feel that medical facilities in a hospital are dependable, they will be willing to pay a higher price, corresponding to with what they receive [39]. Conversely, when they pay high costs, it is usually for better service which will in turn make them rate health care quality higher.

Contrary to some of our results which are consistent with the extant literature, the impact of factor of age in our study stands in contrast with previous findings. Coulter et al. and Keller et al. proved that younger people tend to be more critical in assessing quality of medical care [40,41], but the opposite was concluded in this research. The older appear more critical when giving opinions about healthcare quality. It should be noted, though, that the difference is not really clear as each unit of increase in age only leads to 0.005 points of decrease in healthcare quality (Equation (4)).

It is also noteworthy that having health insurance results in a more negative stance on health care. This may be because, counterintuitive as this might sound, patients may receive services with worse quality when they have insurance. In fact, with health insurance, patients pay less money for the treatment-in some cases, reimbursement rates can be up to $100 \%$ in Vietnam. This could potentially induce medical staff to become less conscientious with insured patients because they do not see a direct turnover to them.

This problem could also be linked to having friends or relatives who have had prolonged treatment also rate quality of treatment at lower levels. The reason might be that they were influenced by the opinions of their friends or relatives, who bought health insurance to alleviate their financial burden during the treatment [34] and had poor impressions about the service quality.

With respect to people's perceptions about public health, the findings separate into two main conclusions. The first one concerns body mass index (BMI): the increase in BMI causes a relative decrease in the probability of good feelings about public health (from $66 \%$ down to $41 \%$ ). This effectively means that when someone is less healthy (represented the risk of being overweight, in this case), they are more likely to project their own concerns on the rest of society, thus feeling pessimistic about the current state of community health.

The second was one of the most intriguing results we have found: an increase in quality of health care services leads to decreased likelihood of optimistic feelings about public health (from $74 \%$ down to $49 \%$ ), contrary to most expectations. However, it can be explained as follows: these two variables are assessed simultaneously by the respondents, and both are influenced by the patients' subjective feelings and perception. When a person has a pessimistic outlook on the status of public health, they will make every effort to choose the best care services for themselves. In Vietnam, it is usually private hospitals or clinics that offer service packages. These packages are mostly high-quality due to modern equipment and responsiveness of the staff. It should be noted that these types of service does not usually come in an affordable price to a sizeable part of the population, and are typically used by 
those of at least over-average income. In fact, if we take into account the fact that costs and quality are mutually influential, as concluded above, we could essentially say: those who earn enough to afford good services are pessimistic about public health, while those who somehow feel better about public health are often not as wealthy and are discontent with the quality of the health care they could access.

This not only, once again, implies a growing gap of inequality among the wealthy and the less fortunate, but also a collective dissatisfaction towards the health care system, in particular, and the governmental system, in general. As such, if Vietnam wishes to sustain its social stability in the long-term, it is indispensable that the Vietnamese government works on improving health care quality by renovating facilities, updating medical equipment, and devising better training programs for the medical personnel. The fact that the current health insurance system and policies are inadequate - if not potentially damaging-in maintaining and promoting equal access to health care is not new and conforms to previous findings [38,42]; thus, it is advised that the government takes an alternate direction in health care reforms. At the same time, thorough attention should be given to the communication of health-related knowledge: health campaigns, rather than consisting of mostly propaganda-style PSA, should be done in a more pragmatic manner in order to raise public health awareness. A suggestion would be to employ young people in media campaigns, as they are flexible and up-to-date with international trends on methods of garnering public attention, and are also more favourable to the current quality of the health system.

\section{Conclusions}

In summary, we would like to conclude our study with two main findings. First, it has been established that better access to health-related knowledge-whether via mass-media health communication or through first-hand or second-hand experiences with medical care from family and friends-positively influence a patient's evaluation of health care service quality. Young people are slightly less critical about service quality; and wealthier patients tend to be more satisfied with the care they receive. Second, people in better shape would have a more optimistic view of public health. Most counterintuitively, it was discovered that favourable perceptions of heath care service quality are linked to a pessimistic view of public health, and vice versa. This could be explained by the fact that people who saw public health as problematic tend to opt for better services, while the rest remains discontent with the quality of services they could afford.

This is problematic to the sustainability of Vietnam's society and calls for governmental intervention. It could be inferred from the above findings that health care reforms must not stop at improving infrastructure and the health insurance system, but should ideally pay close attention to the communication of health care knowledge.

Acknowledgments: The authors would like to thank Vuong and Associates for research assistance during the data collecting and preparing process, particularly Director Dam Thu Ha and Nghiem Phu Kien Cuong.

Author Contributions: The authors contribute equally to the production of the manuscript.

Conflicts of Interest: The authors declare no conflict of interest.

\section{References}

1. Schuster, M.A.; McGlynn, E.A.; Brook, R.H. How good is the quality of health care in the United States? Milbank Q. 1998, 76, 517-563. [CrossRef] [PubMed]

2. Schneider, E.C.; Lieberman, T. Publicly disclosed information about the quality of health care: Response of the US public. Qual. Health Care 2001, 10, 96-103. [CrossRef] [PubMed]

3. Ferlie, E.B.; Shortell, S.M. Improving the quality of health care in the United Kingdom and the United States: A framework for change. Milbank Q. 2001, 79, 281-315. [CrossRef] [PubMed]

4. McGlynn, E.A.; Asch, S.M.; Adams, J.; Keesey, J.; Hicks, J.; DeCristofaro, A.; Kerr, E.A. The quality of health care delivered to adults in the United States. N. Engl. J. Med. 2003, 348, 2635-2645. [CrossRef] [PubMed] 
5. Zurovac, D.; Rowe, A.K.; Ochola, S.A.; Noor, A.M.; Midia, B.; English, M.; Snow, R.W. Predictors of the quality of health worker treatment practices for uncomplicated malaria at government health facilities in Kenya. Int. J. Epidemiol. 2004, 33, 1080-1091. [CrossRef] [PubMed]

6. Sofaer, S.; Firminger, K. Patient perceptions of the quality of health services. Annu. Rev. Public Health 2005, 26, 513-559. [CrossRef] [PubMed]

7. Rooney, A.L.; Van Ostenberg, P.R. Licensure, Accreditation, and Certification: Approaches to Health Services Quality; Center for Human Services, Quality Assurance Project: Bethesda, MD, USA, 1999.

8. Leonard, K.L.; Masatu, M.C. The use of direct clinician observation and vignettes for health services quality evaluation in developing countries. Soc. Sci. Med. 2005, 61, 1944-1951. [CrossRef] [PubMed]

9. Chalkley, M.; Malcomson, J.M. Contracting for health services when patient demand does not reflect quality. J. Health Econ. 1998, 17, 1-19. [CrossRef]

10. Vuong, Q.-H.; Ha, N. Do economic conditions and in-kind benefits make needy patients bond together? Insights from cross-section data on clusters of co-located patients in Vietnam. Biomed. Res. 2017, 28, 6103-6107. [CrossRef]

11. Vuong, Q.H. Economic benefits and treatment progress as determinants of the sustainability of Vietnamese voluntary co-located patients clusters. J. Public Health Res. 2017, 6, 10-17. [CrossRef] [PubMed]

12. Brugha, R.; Zwi, A. Improving the quality of private sector delivery of public health services: Challenges and strategies. Health Policy Plan. 1998, 13, 107-120. [CrossRef] [PubMed]

13. Rao, K.D.; Peters, D.H.; Bandeen-Roche, K. Towards patient-centered health services in India-A scale to measure patient perceptions of quality. Int. J. Qual. Health Care 2006, 18, 414-421. [CrossRef] [PubMed]

14. Cheng Lim, P.; Tang, N.K. A study of patients' expectations and satisfaction in Singapore hospitals. Int. J. Health Care Qual. Assur. 2000, 13, 290-299. [CrossRef]

15. Haddad, S.; Fournier, P. Quality, cost and utilization of health services in developing countries. A longitudinal study in Zaire. Soc. Sci. Med. 1995, 40, 743-753. [CrossRef]

16. Youssef, F.N. Health care quality in NHS hospitals. Int. J. Health Care Qual. Assur. 1996, 9, 15-28. [CrossRef] [PubMed]

17. Khan, M.H.; Hassan, R.; Anwar, S.; Babar, T.S.; Babar, K.S.; Khan, D.I. Patient satisfaction with nursing care. RMJ 2007, 32, 28-30.

18. Naidu, A. Factors affecting patient satisfaction and healthcare quality. Int. J. Health Care Qual. Assur. 2009, 22, 366-381. [CrossRef] [PubMed]

19. Irurita, V. Factors affecting the quality of nursing care: The patient's perspective. Int. J. Nurs. Pract. 1999, 5, 86-94. [CrossRef] [PubMed]

20. Diez Roux, A.V. Investigating neighborhood and area effects on health. Am. J. Public Health 2001, 91, 1783-1789. [CrossRef] [PubMed]

21. Macintyre, S.; Maciver, S.; Sooman, A. Area, class and health: Should we be focusing on places or people? J. Soc. Policy 1993, 22, 213-234. [CrossRef]

22. Currie, C.; Zanotti, C.; Morgan, A.; Currie, D.; de Looze, M.; Roberts, C.; Barnekow, V. Social Determinants of Health and Well-Being among Young People. Health Behaviour in School-Aged Children (HBSC) Study: International Report from the 2009/2010 Survey; Health Policy for Children and Adolescents, No. 6; WHO Europe: Copenhagen, Denmark, 2012.

23. Shaper, A.G.; Pocock, S.J.; Walker, M.; Cohen, N.M.; Wale, C.J.; Thomson, A.G. British Regional Heart Study: Cardiovascular risk factors in middle-aged men in 24 towns. BMJ 1981, 283, 179-186. [CrossRef] [PubMed]

24. Pocock, S.J.; Shaper, A.G.; Cook, D.G.; Packham, R.F.; Lacey, R.F.; Powell, P.; Russell, P.F. British Regional Heart Study: Geographic variations in cardiovascular mortality, and the role of water quality. BMJ 1980, 280, 1243-1249. [CrossRef] [PubMed]

25. Blaxter, M. Health and Lifestyles; Routledge: London, UK, 1990.

26. Smith, G.D.; Morris, J.N.; Shaw, M. The independent inquiry into inequalities in health. BMJ 1998, 317, 1465-1466. [CrossRef] [PubMed]

27. Bakker, M.; Mackenbach, J. Reducing Inequalities in Health: A European Perspective; Routledge: London, UK, 2002.

28. World Health Organization. Equity in Health and Health Care: A WHO/SIDA Initiative; WHO: Geneva, Switzerland, 2006.

29. Haines, A.; Kovats, R.S.; Campbell-Lendrum, D.; Corvalán, C. Climate change and human health: Impacts, vulnerability and public health. Public Health 2006, 120, 585-596. [CrossRef] [PubMed] 
30. Jha, A.; Dobe, M. Personal vis-a-vis social responsibility for disparities in health status: An issue of justice. Indian J. Public Health 2016, 60, 216. [PubMed]

31. MacGregor, J.C.; Wathen, C.N. 'My health is not a job': A qualitative exploration of personal health management and imperatives of the 'new public health. BMC Public Health 2014, 14, 726. [CrossRef] [PubMed]

32. Wiley, L.F.; Berman, M.L.; Blanke, D. Who's your nanny? Choice, paternalism and public health in the age of personal responsibility. J. Law Med. Ethics 2013, 41, 88-91. [CrossRef] [PubMed]

33. Agresti, A. Categorical Data Analysis, 3rd ed.; Wiley: Hoboken, NJ, USA, 2013.

34. Vuong, Q.H. Be rich or don't be sick: Estimating Vietnamese patients' risk of falling into destitution. SpringerPlus 2015, 4, 529. [CrossRef] [PubMed]

35. Batbaatar, E.; Dorjdagva, J.; Luvsannyam, A.; Savino, M.M.; Amenta, P. Determinants of patient satisfaction: A systematic review. Perspect. Public Health 2017, 137, 89-101. [CrossRef] [PubMed]

36. Vuong, Q.H. Health communication, information technology and the public's attitude toward periodic general health examinations. F1000Research 2016, 5, 2935. [CrossRef] [PubMed]

37. Jones, K.; Denham, B.E.; Springston, J.K. Effects of mass and interpersonal communication on breast cancer screening: Advancing agenda-setting theory in health contexts. J. Appl. Commun. Res. 2006, 34, 94-113.

38. Vuong, Q.H.; Vu, Q.H.; Vuong, T.-T. What makes Vietnamese (not) attend periodic general health examinations? A 2016 cross-sectional study. Osong Public Health Res. Perspect. 2017, 8, 147-154. [CrossRef] [PubMed]

39. Stein, S.M.; Day, M.; Karia, R.; Hutzler, L.; Bosco, J.A., III. Patients' perceptions of care are associated with quality of hospital care: A survey of 4605 hospitals. Am. J. Med. Qual. 2015, 30, 382-388. [CrossRef] [PubMed]

40. Coulter, A.; Jenkinson, C. European patients' views on the responsiveness of health systems and healthcare providers. Eur. J. Public Health 2005, 15, 355-360. [CrossRef] [PubMed]

41. Keller, P.A.; Lehmann, D.R. Designing effective health communications: A meta-analysis. J. Public Policy Mark. 2008, 27, 117-130. [CrossRef]

42. Vuong, Q.H.; Nguyen, H.; Vuong, T.-T. Health insurance thresholds and policy implications: A Vietnamese medical survey in 2015. Biomed. Res. 2017, 28, 2432-2438.

(C) 2017 by the authors. Licensee MDPI, Basel, Switzerland. This article is an open access article distributed under the terms and conditions of the Creative Commons Attribution (CC BY) license (http:/ / creativecommons.org/licenses/by/4.0/). 